\title{
SIMPLE MODEL OF PELLET COMBUSTION IN RETORT BURNER
}

Combustion of the solid fuel in the burner is an important issue when discussing the CFD simulation of combustion in automatic boiler. In the present work is employed a simplified method for modeling the fuel bed, which is based on mass and heat balances in order to simplify the simulation of combustion in pellet boiler. The model for solid fuel combustion in a burner is created for the purpose of automatic boiler simulations. Such approach does not require a detailed bed model of fired solid fuel. A simple model of the bed can be very useful for designers and engineers of automatic boilers. The described approach to modeling the combustion process in a burner helps to shorten the calculation time and simplify the model of pellet combustion in various types of automatic boilers for households.

Keywords: Simulation, CFD, combustion, biomass, pellet, boiler.

\section{Introduction}

CFD simulations may help to increase understanding and provide detailed prediction of combustion taking place in a boiler. However, modeling of combustion is more complex in biomass boilers than in gas or oil-fired boilers, due to the complexity of the heterogeneous reactions in the bed, the turbulent reactive flow in the freeboard and the very strong coupling between those two regions. However, it is usually not required to describe in depth and in every detail all phenomena that occur in a combustion system. Instead, CFD calculations should give an approximate view of system behavior, help in troubleshooting and provide insights necessary to fine-tune the system's operation, as well as give assistance when dealing with new designs [1].

From an engineer point of view a detailed model of combustion process in a burner is too complicated to be useful, as it requires great amount of time and effort to set it up, run, and analyze its results. Therefore it can be useful to introduce some assumptions in order to simplify a boiler simulation. From an overall point of view on a boiler as a unit, only integral factors like heat and mass transfer in the bed and the boiler are relevant. A simplified method of bed modeling based on thermal and mass balances was employed in this work to describe pellet combustion process in the simulation of an experimental $20 \mathrm{~kW}$ boiler. The predictions from CFD simulation were compared with the analytic results from thermal and mass analysis of the combustion process. The model employed in this work may be readily adapted for the modeling of other solid fuel burners and boiler designs. Several combustion parameters need to be defined in order to a practicable model would be achieved.

\subsection{Combustion process in a retort burner}

The analyzed boiler (Fig. 1) is equipped with a retort burner, which works on underfeeding principle. Fuel (e.g. pellets) is fed from a fuel tank through a horizontal pipe by a feeding screw. The burner elbow changes the direction of movement and pellets are slowly pushed from the bottom into the mouth of the burner, where the combustion process starts. From long-time viewpoint, the pellet boiler operation is a steady process. In fact, the pellet supply to the burner is discontinuous, because the feeder is in operation for tens of seconds and then certain time in rest during the next pellet batch is fired. The primary air is usually blown into the feeder, but also directly to the fired pellets through slits in the burner mouth. The fuel is gradually fed to the bed, where it is heated and gradually releases volatile gases [2]. Depending on the specific fuel, volatile gases start to be released already from $150-200{ }^{\circ} \mathrm{C}$. Gases then pass through the hot upper layer of bed, which leads to their ignition and subsequent burning in the combustion chamber [3]. The upper layer of bed consists mainly of fixed carbon and non-combustible inorganic material, with inter-particle space filled by gases.

\footnotetext{
* ${ }^{1}$ Jozef Micieta, ${ }^{2}$ Jiri Hajek, ${ }^{1}$ Jozef Jandacka

${ }^{1}$ Department of Power Engineering, Faculty of Mechanical Engineering, University of Zilina, Zilina, Slovakia

${ }^{2}$ Department of Process and Environmental Engineering, Faculty of Mechanical Engineering, Brno University of Technology, Brno, Czech Republic E-mail: jozef.micieta@fstroj.uniza.sk
} 
Small part of the combustible gases burns in the bed, but the main combustion process takes place in the combustion chamber above the burner (freeboard). Burned pellets, or their parts are pushed away from the bed surface and then to burner edge, where they gradually burn out. The edge of the retort burner is usually made of cast iron, which resists well the hot environment and accumulates heat, so it creates favorable conditions for fuel gasification. Oxygen in the primary air, which is not used for the char combustion, is preheated so that there is no problem with incomplete oxidation of combustible gases in the combustion chamber [4]. Residues (ash and unburnt fuel) are either (in the case of fine particles) blown away by the combustion air or (heavier particles) are gradually pushed out of the burner to the ashtray. Secondary air is introduced into the combustion chamber at a certain height above the burner through nozzles in the intermediate wall, which leads to the burnout of remaining combustible gases. Before secondary air blows into the combustion chamber, it is heated in the distribution channel, pipes and intermediate wall.

\subsection{Biomass fuel}

Ultimate and proximate analysis of the fuel that is used in the model is shown in Table 1. More physical and chemical properties of various biomass fuels could be found in databases, which are quoted in [5] or e.g. [6] and in similar work [7]. Parameters of fuel like moisture, ash content, ratio of char and volatile combustible compounds, and calorific value are obtained in proximate analysis, which is performed experimentally. From the point of view of energy content it is more practical and useful as the ultimate analysis of fuel and it defines fuel parameters necessary as input for CFD simulations.

Proximate analysis is in this work directly used to define composition of gases entering the combustion chamber. As noted above, primary air is supplied together with fuel to the bed. Gaseous products of fuel drying and devolatilization are thus mixed with primary air. This defines the composition of gas entering the combustion chamber.

\section{CFD model description}

The present CFD model was set up within commercial code Ansys Fluent, but it would be the same in other software as well. The modeling of biomass boiler includes two main areas of interest: 1) combustion process of biomass in the bed and 2) homogeneous reactions and heat transfer in the combustion chamber (freeboard). These two processes are strongly coupled, as freeboard reactions depend on the gases leaving the bed, and as the radiative heat flux emitted by flames above the bed drives the processes inside the bed [1].

Combustible gases in reality begin to be released at the so-called devolatilization temperature, which according to the Ion's work [8] is about $330{ }^{\circ} \mathrm{C}$ (about $600 \mathrm{~K}$ ). With further increase of temperature, the composition of the released gases changes.

Thus, there is apparent that devolatilization process is strongly coupled to the temperature in combustion chamber, which in turn depends on the amount and composition of the released volatile gases. Therefore, in the present simplified model it is necessary to select a reference temperature, which is key to determining the composition of released gases [7]. There was chosen a temperature level of $600 \mathrm{~K}$ (about $330{ }^{\circ} \mathrm{C}$ ) to estimate the composition of introduced volatile gases, adopting the individual mass fractions according to Ion [8] or Thunman [9]. For simplification, the model assumes devolatilization like an instantaneous phenomenon of thermal transformation of fuel. Volatile gases are represented by $\mathrm{CO}, \mathrm{CO}_{2}, \mathrm{H}_{2}, \mathrm{H}_{2} \mathrm{O}$, plus $\mathrm{CH}_{4}$ representing light hydrocarbons, and finally $\mathrm{C}_{6} \mathrm{H}_{6}$ representing heavy hydrocarbons (tar), optionally also $\mathrm{NH}_{3}$.

The amount of nitrogen in a majority of biomass fuels is below $1 \%$, (although some phytomass fuels may contain up to $4 \%$ ). It reacts by endothermic reaction (the energy gain is negative). The reaction can be neglected, because the relative energy gain is very small. Some authors have defined the biomass by a substitutive substance with the chemical formula $\mathrm{C}_{6} \mathrm{H}_{\mathrm{a}} \mathrm{O}_{\mathrm{b}}$. It replaces biomass in dry, ash-free state, where $a$ and $b$ are coefficients [5 and 10]. For this substance are defined physical parameters similar to the real for biomass. The devolatilization model of biomass is then described by the following reaction (1).

Approximate composition and properties of the employed fuel

\begin{tabular}{|ll|ll|ll|}
\hline Ultimate analysis & & Proximate analysis & & Bed and particle parameters \\
\hline Carbon & $52.0 \mathrm{wt} \%$ & Moisture & $8.5 \mathrm{wt} \%$ & Particle diameter & $6 \mathrm{~mm}$ \\
Hydrogen & $6.8 \mathrm{wt} \%$ & Ash & $0.6 \mathrm{wt} \%$ & Average pellet length & $12 \mathrm{~mm}$ \\
Oxygen & $41.0 \mathrm{wt} \%$ & Fixed carbon & $16.2 \mathrm{wt} \%$ & Void fraction & 0.4 \\
Nitrogen & $0.2 \mathrm{wt} \%$ & Volatile & $74.7 \mathrm{wt} \%$ & Net calorific value & $18.3 \mathrm{MJ} / \mathrm{kg}$ \\
\hline
\end{tabular}




$$
\begin{aligned}
& \mathrm{C}_{6} \mathrm{H}_{a} \mathrm{O}_{b}=x_{\text {char,ashfree }} \mathrm{C}+x_{2} \mathrm{CO}_{2}+x_{3} \mathrm{H}_{2}+ \\
& +x_{4} \mathrm{H}_{2} \mathrm{O}+x_{5} \mathrm{CH}_{4}+x_{6} \mathrm{C}_{6} \mathrm{H}_{6}
\end{aligned}
$$

where $x_{\mathrm{i}}$ is the number of moles of a given species involved in the process. After gasification, only a solid substance remains in the bed. This charcoal can be considered for wood pellets as pure carbon, because the ash content is usually below $1 \%$. Sulphur content is at trace level, so it is neglected as well. Char combustion is a complex process that is affected by the fuel composition, particle shape and boiler conditions. A simplified model is used by Porteiro [11], which considers a heterogeneous reaction of char to form $\mathrm{CO}$ and $\mathrm{CO}_{2}$ (2), where the ratio of the $\mathrm{CO} / \mathrm{CO}_{2}$ formation rate depends on the temperature (3). A representative char combustion temperature of $1373 \mathrm{~K}$ (about $1100{ }^{\circ} \mathrm{C}$ ) is employed in this work to estimate the composition of the char combustion products [7].

$$
\begin{aligned}
& \eta \mathrm{C}+\mathrm{O}_{2} \rightarrow 2(\eta-1) \mathrm{CO}+(2-\eta) \mathrm{CO}_{2} \\
& \eta=\frac{2\left(1+4 \cdot 3 e^{(-3390 / T)}\right)}{\left(2+4 \cdot 3 e^{(-3390 / T)}\right)}
\end{aligned}
$$

The present work simulates combustion at nominal power of the boiler, as the most representative operating condition. In the long-term point of view, the combustion can be considered as continuous steady process. Adopting this assumption implies that the various zones in the boiler, where certain processes dominate (such as heating, drying, gasification, combustion of volatile gases and char combustion...) are fixed in space. Then the overall combustion process can be considered as steady. Main boundary conditions of the model then include mass flow inlet defined at the fuel and air inlet (burner), secondary air inlet and flue gas outlet to the chimney (pressure outlet).

\subsection{Model of fuel conversion - bed model}

As noted above, it is evident that the most complicated processes occur in the burner. The top layer of burner volume that contains burning pellets is called the bed. Within the bed take place several phenomena, from the initial heating of fuel, through its drying, devolatilization, gas combustion and fixed carbon burnout. Reactants, which include the primary combustion air and the solid fuel, are fed to this bed layer. In the computational model devised in this work, the bed is a part of the computational domain and there is no separate bed model to define the boundary conditions, similarly as in [1].

If boiler is considered as a device for transformation of chemically stored energy into heat carried by hot utility water, then burner is a device for fuel transformation to combustible gases and consequently to flue gases, while the thermal energy is released. The subsequent combustion of devolatilized fuel takes place in the freeboard (combustion chamber). As detailed description of the processes occurring in the burner is not required in this work, the burner may be considered as the source (inlet) of flammable gases, thermal energy and primary combustion air, the oxygen in which is already partially consumed. Gas leaves the bed at a certain temperature, which is higher than the devolatilization temperature. If the gas species were inserted into the computational domain through mass sources, the FLUENT software would provide no option to specify their inlet temperature. This problem can be eliminated by assumption that the volatile gases enter the domain through the inlet boundary. The inlet however may not be located at the interface of the bed and the freeboard, as in that case the bed would behave as a reflective surface (diffuse or specular). Thus it is better to place the inlet below the porous fuel bed.

A substitution for the heterogeneous char oxidation in the bed (2) is one of major simplifications, which can be adopted only for automatic boilers. This reaction was replaced by volatile compounds $\left(\mathrm{CO}\right.$ and $\left.\mathrm{CO}_{2}\right)$ and a heat source in the bed. The number of moles of gaseous species and the released energy during reaction were calculated externally, according to equations (2) and (3) [1 and 7]. Volatile compounds produced during the heterogeneous char reaction were incorporated into the mass flow inlet of species and the energy generated by char oxidation reaction was considered as the heat source in the bed. The simplified model then considered only homogeneous gas reactions.

One role of the bed was to distribute fluid flow on the interface with freeboard evenly across the burner. Furthermore, the bed provided space and time to heat up the gas. These two effects of the bed are closely coupled. The pellets fill up the bed volume and they had the shape of cylinders with known properties. With this assumption, it was possible to replace the bed volume by a porous zone. There was necessary to specify parameters of the porous zone to generate a correct pressure loss in the gas passing through the pellets.

Different flow regimes were expected in the boiler due to its complex geometry. The gases were practically still in some regions and, on the contrary, high gas velocities and fully turbulent flow were expected in areas such as the flame or secondary air injections. Beneath the bed was primary air inlet and various thermo-chemical processes take place in the bed, thus there was also expected turbulent flow. The realizable $k-\varepsilon$ model was employed to account for the effect of turbulence due to its proven effectiveness in industrial applications [12 and 13].

In this work the modeling of a packed bed was performed without considering channeling effect. In turbulent flows, packed beds were modeled using both permeability $\alpha$ (a viscous resistance coefficient is $1 / \alpha$ ) and an inertial loss coefficient $C_{2}$. One technique for deriving the appropriate values of the porous properties involves the use of the Ergun equation [14]. It is a semiempirical correlation applicable over a wide range of Reynolds numbers and for many types of packing. 
The effect of the bed porosity on the gas flow was introduced by the addition of a source term $S_{i}$, calculated by the formula (4), into the momentum equation. Three parameters were needed in the CFD code to evaluate the source term: permeability $\alpha$, inertial losses coefficient $C_{2}$ and porosity $\mathcal{E}$. The source term was composed of two parts: a viscous loss term (Darcy`s, the first term in equation (4)), and an inertial loss term (the second term in the same equation (4)) [15]. To cover the present case of simple homogeneous and isotropic porous media, it was sufficient to use the same porous properties in the whole bed volume.

$\nabla p=S_{i}=-\left(\frac{\mu}{\alpha} \nu_{1}+C_{2} \frac{1}{2} \rho_{p}|v| v_{i}\right)$

$\left(k g \cdot m^{-2} \cdot s^{-2}\right)$

Where $S_{i}$ is the source term for the $i$ th $(x, y$, or $z)$ momentum equation, $|\nu|$ is the magnitude of the velocity, $\mu$ is the viscosity. In equations (5) and (6) that define permeability and inertial loss coefficient, $d_{e q}$ is the equivalent particle diameter and $\mathcal{E}$ is the void fraction, defined as the volume of voids divided by the volume of the packed bed region. Comparing Darcy`s equation and equation for inertial loss in the porous media with Ergun equation, the permeability and inertial loss coefficient in each component direction may have been identified as:

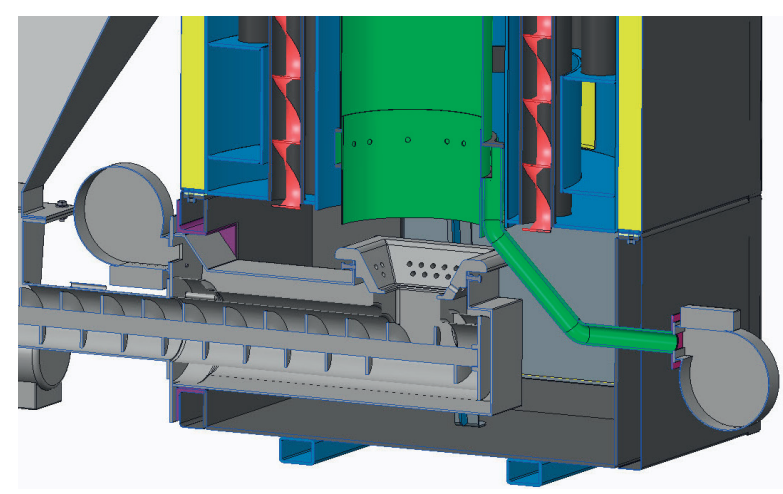

Fig. $13 D$ geometry of the burner and the freeboard
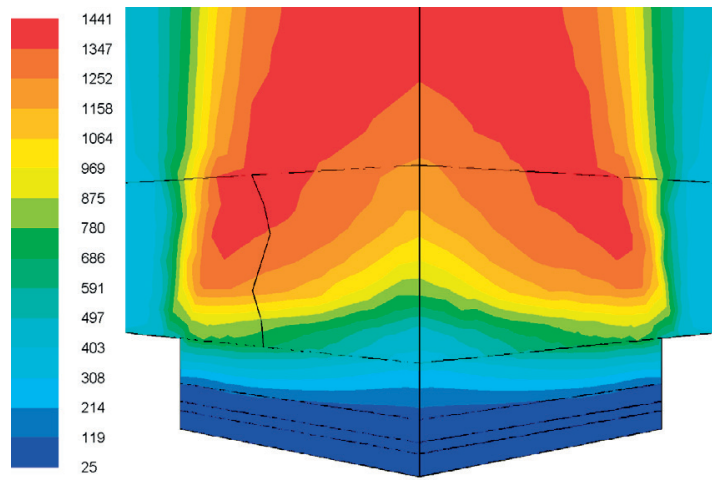

Fig. 3 Temperature $\left({ }^{\circ} \mathrm{C}\right)$ in bed, without radiation
$\alpha=\left(\frac{\Psi^{2} d_{e q}^{2}}{150} \frac{\varepsilon^{3}}{(1-\varepsilon)^{2}}\right) \quad\left(m^{2}\right)$

$C_{2}=\frac{3,5}{\Psi d_{e q}} \frac{(1-\varepsilon)}{\varepsilon^{3}} \quad\left(m^{-1}\right)$.

Permeability (5) and inertial loss coefficients (6) were estimated by the Ergun equation using the mean diameter $D_{p}$ of the fuel particles [15]. The sphericity $\Psi$ and the spherical equivalent diameter $d_{e q}$ were calculated from fuel parameters shown in Table 1 using formulas (7) and (8):

$\Psi=\frac{\pi^{1 / 3}\left(6 V_{p}\right)^{2 / 3}}{A_{p}} \quad(-)$,

$d_{e q}=D_{p}\left(\frac{3 L_{p}}{2 D_{p}}\right)^{1 / 3} \quad\left(m^{2}\right)$

The fuel in the burner was modeled by 4 layers with different porosity and total height $20 \mathrm{~mm}$, which were discretized by several layers of hexahedra. Mesh of bed should be sufficiently fine in order to cover fluid flow changes (Fig. 2).

The computational model used the symmetry of the boiler, and therefore it modelled only $1 / 4$ of the boiler. The boundaries of the model in the radial direction were defined as symmetry planes,

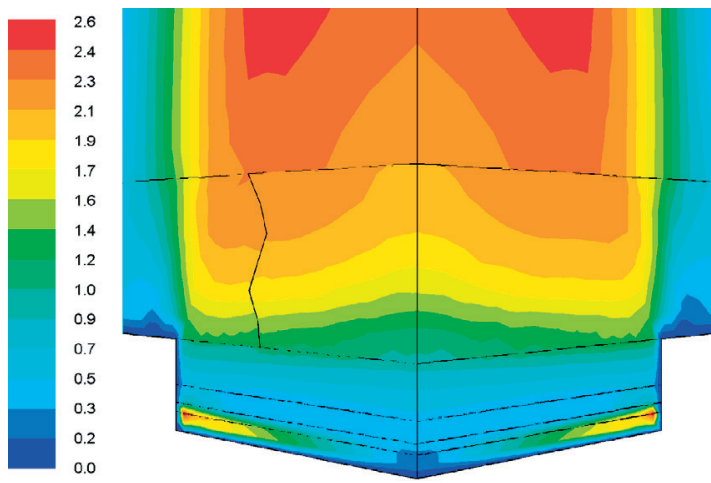

Fig. 2 Velocity $(\mathrm{m} / \mathrm{s})$ in the bed
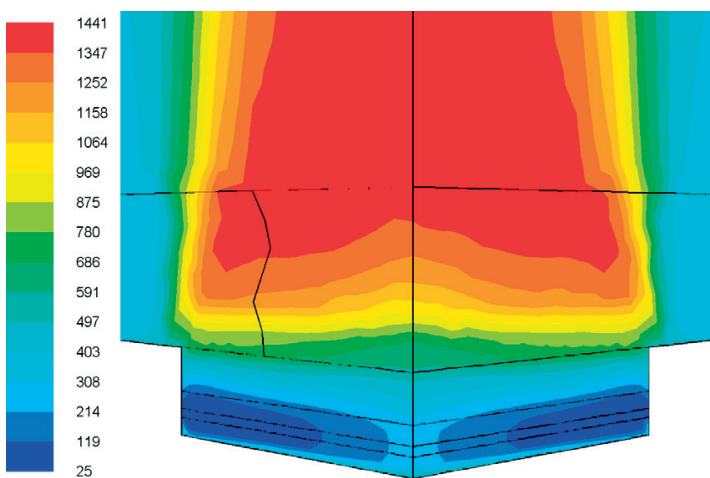

Fig. 4. Temperature $\left({ }^{\circ} \mathrm{C}\right)$ in bed, with radiation 
as there was no tangential flow. The wall of the burner, which was in contact with the bed, was considered adiabatic.

A significant effect on the temperature of combustion chamber had the radiative heat transfer in the fuel bed. Radiation increased the temperature inside the bed, as shown by the temperature fields on the symmetry planes in Figs. 3 and 4.

In the model set-up, there was important to set the absorption coefficient of the burner walls equal to unity (black body). Otherwise, all radiative flux would be reflected back. During the model development it was also found as very important to carefully design the porous fuel volume and the primary air inlet, because the area of the input boundary leads to radiation losses. Therefore the inlet area should be small and shielded from the direct radiative flux of the combustion chamber. It also had to ensure uniform velocity and mass flux distribution on the bedfreeboard interface. In simulations, several design alternatives for the supply of reactants were tested. The most appropriate method in this particular burner was from placing the inlets on the burner perimeter. The inlet had the shape of a narrow slit in under the porous bed. The space under the bed was open to horizontal flow, which helped to distribute the fluid flow. This solution ensured almost uniform flow in the layer above it.

\section{Conclusion}

The described model is substitution of combustion process and it greatly simplifies the modeling approach for pellet combustion and also it is simple and easy to apply for a user of CFD software. This model can be used for simulation in a relatively simple way and it is able to predict the general behavior of solid fuel-fired boilers. In developing the model, it is necessary to consider the impact of the assumptions which may vary depending on the design of the burner and boiler.
The limitations of the bed model include the assumption that the reactants are well mixed with each other and that the heterogeneous combustion process is also uniform in space. Another important limitation of the model is that it considers constant temperatures of devolatilization and of char combustion. Perhaps the main simplifying assumption is that the production of volatiles in the bed is independent of the conditions in the combustion chamber. An advantage is that the model bed is set up directly in the CFD model and does not require programming of external libraries.

The present model does not substitute more advanced models and tools that can be used to design biomass combustion systems, such as three dimensional bed, transient modeling, solid to gas conversion or bed particles feeding. These all are however quite complex tasks, which require the implementation of external libraries. The work introduces the model that may provide the useful tool in the design of small automatic boilers, where fuel consists of well-defined pellets, the fixed bed is small relative to the combustion chamber, and where high development costs preclude the application of more sophisticated tools. Although the described model was developed for the retort burner, the model can be applied also on wide range of various pellet burners and boiler.

\section{Acknowledgement}

This article has been prepared within the framework of the project R\&D - APVV-0458-11 "Solving issues with low-melting ash during the biomass combustion". The author JH gratefully acknowledges financial support of the Ministry of Education, Youth and Sports within the programme "National Sustainability Programme I“, project NETME CENTRE PLUS (LO1202).

\section{References}

[1] COLLAZO, J. et al.: Numerical Simulation of a Small-scale Biomass Boiler. Energy Conversion and Management, 2012, vol. 64, pp. 87-96.

[2] NOSEK, R. et al.: The Measurement of Emission during Biomass Combustion in a Small Heat Source (in Slovak). 32. stretnutie katedier mechaniky tekutín a termomechaniky, VysokeTatry : Tatranska Lomnica : Zilinska univerzita, 2013, pp. 205-208.

[3] KOLONICNY, J. et al.: Progress of Proper Heating (in Czech). Ostrava : Technicka univerzita Ostrava : Vyzkumne energeticke centrum, 2010, 131 p., ISBN 978-80-248-2255-6.

[4] LYCKA, Z.: Wood Pellet II : Combustion in Small Heat Source (in Czech), $1^{\text {st }}$ ed., Krnov: LING Vydavatelstvi, 2011,71 p., ISBN 978-80-904914-1-0.

[5] KOPPEJAN, J., VAN LOO, S.: The Handbook of Biomass Combustion and Co-firing. London: Earthscan Publications, 2010, 442 p., ISBN 978-1-84971-104-3.

[6] JANDACKA, J. et al.: Biomass Like Energy Source : Potential, Sorts, Balance and Fuel Properties (in Slovak), $1^{\text {st }}$ ed., Zilina : Juraj Stefun : GEORG, 2007, 241 p., ISBN 978-80-969161-3-9.

[7] GOMEZ, M. A., et al.: Simulation of the Effect of Water Temperature on Domestic Biomass Boiler Performance. Energies, 2012, vol. 5, No. 12, pp. 1044-1061. 
[8] ION, I. V. et al.: A Biomass Pyrolysis Model for CFD Application. J. of Thermal Analysis and Calorimetry, 2013, vol. 111, No. 3, pp. 1811-1815.

[9] THUNMAN, H.: Principles and Models of Solid Fuel Combustion. Goteborg : Chalmers University of Technology, 2001.

[10] SHARMA, A. K. et al.: Modelling Product Composition in Slow Pyrolysis of Wood. SESI Journal, 2006, vol. 1, No. 16, pp. 1-11.

[11] PORTEIRO, J. et al.: Numerical Modeling of a Biomass Pellet Domestic Boiler. Energy \& Fuels, 2009, No. 23, pp. 1067-1075.

[12] KLASON, T. et al.: Investigation of Radiative Heat Transfer in Fixed Bed Biomass Furnaces. Fuel, 2008, vol. 87, No. 10-11, pp. 2141-2153.

[13] ZAHIROVIC, S. et al.: Advanced Gas Phase Combustion Models: Validation for Biogases by Means of LES and Experiments as well as Application to Biomass Furnaces. $7^{\text {th }}$ European Conference on Industrial Furnaces and Boilers, Porto: CENERTEC, 2006.

[14] ERGUN, S., ORNING, A. A.: Fluid Flow through Randomly Packed Columns and Fluidized Beds. Industrial \& Engineering Chemistry, 1949, vol. 41, No. 6, pp. 1179-1184.

[15] SAS IP, INC. ANSYS Fluent User's Guide, U.S.A., 2013, 2692 p. 